\title{
Negative pressure therapy for the treatment of complex wounds
}

\section{Terapia por pressão negativa no tratamento de feridas complexas}

\author{
Renan Victor Kümpel Schmidt Lima'; Pedro Soler Coltro, ACBC-SP1; Jayme Adriano Farina Júnior¹.
}

\section{A B S T R A C T}

The objective of this study is to evaluate the effectiveness of negative pressure therapy (NPT) in the treatment of complex wounds, with emphasis on its mechanisms of action and main therapeutic indications. We searched the Pubmed / Medline database for articles published from 1997 to 2016, and selected the most relevant ones. The mechanisms of action of NPT involveboth physical effects, such as increased perfusion, control of edema and exudate, reduction of wound dimensions and bacterial clearance, and biological ones, such as the stimulation of granulation tissue formation, microdeformations and reduction of Inflammatory response. The main indications of NPT are complex wounds, such as pressure ulcers, traumatic wounds, operative wound dehiscences, burns, necrotizing wounds, venous ulcers, diabetic wounds, skin grafts, open abdomen, prevention of complications in closed incisions and in the association with instillation of solutions in infected wounds.

Keywords: Negative-Pressure Wound Therapy. Wounds and Injuries. Wound Closure Techniques. Pressure Ulcer. Surgical Wound Dehiscence.

\section{INTRODUCTION}

$S_{c}^{\text {then }}$ tudied since antiquity, wounds still represent a challenge to health professionals. Of diverse etiology and clinical presentations, this pathological entity has always been prevalent in the different cultures, receiving varied treatments in light of the knowledge available in each period.

At present, wounds considered to be difficult to treat, the so-called complex wounds', have received increasing attention from physicians and nurses (directly involved in the care, treatment and use of new technologies), as well as from health managers (concerned with the impact that wound treatment generates on institutional costs). The increase in the prevalence of such wounds is mainly due to aging of the population and to trauma in large urban centers.

The onset of a complex wound raises morbidity and mortality rates, increases overall treatment costs (material and human resources), and leads to longer hospital stays. In this context, it is mandatory for the surgeon to know alternatives that can accelerate the wound's repair process, allowing the patient to be discharged earlier and to return to daily activities.

To this end, negative pressure therapy (NPT) or subatmospheric pressure therapy, introduced commercially after the studies of Argenta and Morykwas in 19972, is an important adjuvant method in the treatment of wounds with the main proposal of accelerating the repair process and preparating the wound bed for its definitive coverage through the various methods of tissue reconstruction.

The aim of this study is to review the literature on NPT in the treatment of complex wounds, with emphasis on its mechanisms of action and main therapeutic indications.

\section{METHODS}

We reviewed the literature in the Pubmed/ Medline database, including original articles and systematic reviews, published between 1997 and 2016. The descriptors used were "negative pressure therapy", isolated or associated with "wound", "ulcer", "pressure sore", "trauma", "dehiscence", "burn", "venous ulcer", "diabetic wound", "open abdomen", "skin graft", "prevention" and "instillation". We selected the most relevant articles and grouped the evidence to summarize their recommendations.

\section{NPT PRINCIPLES AND EQUIPMENT}

NPT is a type of active wound treatment that promotes healing in a humid environment by means of controlled and locally applied subatmospheric pressure.

1 - Ribeirao Preto Medical School, University of Sao Paulo, Division of Plastic Surgery, Ribeirao Preto, Sao Paulo State, Brazil. 
The NPT is composed of an interface material (foam or gauze), through which subatmospheric pressure is applied and the exudate is removed. This material is in contact with the wound bed in order to cover its entire length, including tunnels and cavities. The interface material is covered by a transparent adhesive film, which wholly isolates the wound from the external medium. A suction tube is connected to that system and the exudate reservoir, which is adapted to a computerized device. This device may allow the programming of parameters to provide a subatmospheric pressure in the wound bed, has an audible alarm which indicates possible leakage of air from the dressing, and may indicate the need to exchange the reservoir.

Currently, in Brazil, there are several models and brands of commercial dressings and NPT-based devices. Such brands have differences between them, like the type of therapy available, the interface material, the reservoir, the computerized device (therapy programming, audible alarms, etc.), type of installation (hospital or home), among others.

Regarding the type of therapy, subatmospheric pressure can be administered continuously (without interruption), intermittently (with programmed interruption cycles interspersed with therapy), or associated with instillation of solutions (with scheduled instillation cycles interspersed with cycles of removal of the solution and cycles of therapy). Intermittent therapy aims to accelerate the formation of granulation tissue, and instillation therapy is indicated for the treatment of infected wounds ${ }^{3,4}$.

The interface material may be composed of foam or gauze. There is evidence that both provide the NTP's benefits, with some particularities ${ }^{3,5-8}$. The vast majority of the foams are composed of polyurethane, with pores with diameters ranging from 400 to 600 microns (which facilitate the transmission of suction forces to the tissue and drainage of the exudate). The foams have a greater elasticity, which favors their fitting to the wound bed, and allows greater contraction of the wound, optimizing the approximation of its edges. However, the granulation tissue may grow into the pores of the foam, which may cause minor trauma and pain during withdrawal, especially if held for more than three days in the wound bed.

The gauze is composed of cotton fibers arranged in multiple layers. Granulation tissue generally does not grow into gauze fibers, deeming removal less painful. It can also be impregnated with antimicrobial solution. However, the porosity of the different tissue layers is not coincidental (which may hinder the transmission of suction forces to the tissue and exudate drainage). Because it has less elasticity, it leads to less contraction of the wound and the approximation of the edges is more limited.

Regarding the histological and morphological characteristics, there is evidence that foam and gauze healings are similar ${ }^{3,6-8}$. In clinical practice, some authors claim that foamed NPT is associated with faster tissue granulation formation and greater contraction of wound edges compared to NPT with gauze ${ }^{6,7}$, but further clinical studies are required to confirm such characteristics.

The foams have different sizes and forms of presentation, some having particularities related to their main indication. The conventional foam is composed of polyurethane, but there are polyurethane foams impregnated with silver for use on infected wounds. There are also foams composed of polyvinyl alcohol that have the advantage of having less adherence to the bed, being indicated for use on skin grafts and in cavitations or tunnelled wounds, since their removal is facilitated. For use in the abdominal cavity, in contact with viscera, there are foams that have extensions with multipierced plastic protection associated with pre-cut foams. Instillation therapy of solutions for treatment and cleaning of infected wounds may be associated with NPT. In addition, other conformations of the foam may facilitate its use, such as those that already come precut and those that allow the application of NPT in more difficult places of the body as in plantar wounds, since it allows the adaptation of the connector far from the lesion, allowing patients to walk.

\section{INSTALLATION OF NPT}

Regarding the type of NPT installation, there are devices that require patient hospitalization and 
others that allow the application of NPT at home regimen. The recommendation of the manufacturers is that dressing changes should be made every 48 to 72 hours, since uses for longer periods result in saturation of the foam or the gauze, with a decrease in adequate exudate drainage capacity, reducing treatment efficacy. The exchange of the reservoir, in some brands, is independent of the change of dressing, allowing rationalization of resources. The end of treatment is determined by the finding of favorable local conditions, i.e., when the wound bed is adequately prepared for subsequent skin coverage (by tissue reconstruction methods such as grafts and flaps) or when there is complete healing and wound closure.

The outpatient installation can be performed in the office room itself, and is indicated for superficial and non-painful wounds. The dressing is coupled to a portable, battery-operated device that is responsible for maintaining subatmospheric pressure.

The hospital installation can be done in the patient's bed or in the operating room, with anesthesia, the latter indicated for deeper and more painful wounds, or when there is a need for association with other procedures, such as debridement of devitalized tissues.

\section{NPT MECHANISMS OF ACTION}

The application of NPT provides uniform subatmospheric pressure in the wound bed and its mechanisms of action involve both biological and physical effects.

\section{Biological Effects}

a) Change in cytoskeletal conformation

The application of NPT on a wound causes a deformation of the cellular cytoskeleton (microdeformations), responsible for triggering potent stimulation of cell proliferation and angiogenesis ${ }^{5}$. This is the principle associated with the mechanism of action of tissue expanders and bone elongation through osteogenic distraction. This stimulation to the cell proliferation associated with the tension on the cells was proven in vitro in a study realized by Huang et al., in $1998^{9}$. b) Stimulation of granulation tissue formation

After application of NPT, there is an increase in the number of capillaries in the wound bed, in addition to the deposition of connective tissue and extracellular matrix, which together form the granulation tissue. Chen et al. carried out an experimental study comparing the presence of new vessels in biopsies of wounds treated with NPT and with conservatively. In the determined periods (six and 24 hours, three and six days), the density of capillaries in the group submitted to NPT was significantly higher when compared to the control group $(p<0.01)^{10}$.

c) Reduction of local inflammatory response

It is believed that the use of NPT results in a control of the acute inflammatory response by the clearance of pro-inflammatory cytokines and proteolytic enzymes (membrane metalloproteinases) present in the wound exudate, which are responsible for the degradation of the extracellular matrix and apoptosis. An experimental study by Norbury et al., with a porcine model, evaluated the serum and wound bed dosage of inflammatory cytokines. The authors found lower serum gamma interferon levels (INF-gamma) 12 and 36 hours after injury in animals submitted to NPT than in the control animals $(p<0.05)$. In the wound bed, levels of interleukin 8 (IL-8) were also lower after 12 hours in the experimental group $(p<0.05)$. Other cytokines such as transforming growth factor beta (TGF-B) and tumor necrosis factor alpha (TNF alpha) also showed reduction in the wound bed ${ }^{11}$.

\section{Physical Effects}

a) Increased blood flow to the wound

The application of NPT increases the blood flow to the wound, consequently stimulating the formation of granulation tissue. Through Doppler ultrasound studies², Argenta et al. demonstrated that blood flow increases in the tissues adjacent to the wound with NPT, the highest flow velocity being observed with subatmospheric pressure of $125 \mathrm{mmHg}$. On the other hand, some experimental studies ${ }^{12,13}$ have shown that the application of excessive subatmospheric 
pressure has an opposite effect, and may even reduce local blood flow.

\section{b) Reduction of edema and control of exudate}

The exudate present in the wound bed can macerate the edges of the wound, interfering with the healing process, besides being a medium conducive to the proliferation of microorganisms. Similarly, edema is detrimental because it impairs the perfusion of nutrients and oxygen from the capillaries to the wound bed. NPT removes variable amounts of wound exudate, reducing tissue edema and promoting the restoration of vascular and lymphatic flow, a factor that explains the increase in local blood perfusion and the improvement of the nutrients and oxygen supply².

\section{c) Reduction of wound dimensions}

The application of NPT approaches the edges of the wound by means of a centripetal force, leading to the diminution of its dimensions by tissue contraction ${ }^{3,14}$. In 2004, Moues et al. conducted a controlled, randomized clinical study and verified a significant reduction in wound size of 3.8\% per day for patients using NPT and $1.7 \%$ per day for patients wearing gauze soaked with saline $(p<0.05)^{15}$.

\section{d) Cleansing of bacterial load}

The bacteria present in the wound compete for the nutrients and oxygen that would be destined to tissue repair, hampering the healing process ${ }^{2}$. The clearance of the wound's bacterial load, however, is a controversial subject in the literature. While some studies $^{2}$ demonstrated a reduction in the number of bacteria with the use of NPT, other ${ }^{15,16}$ did not show significant alterations in the bacterial load of wounds treated by this method.

\section{NPT INDICATIONS}

In the literature, it is possible to find several indications for the application of NTP, with good results reported both in randomized, controlled clinical studies, prospective and retrospective cohorts, and in studies with less strength of evidence (clinical series and case reports).
The main indications comprise: a) complex wounds: pressure ulcers, traumatic wounds, surgical wounds (dehiscences), burns, necrotizing wounds, diabetic wounds, venous ulcers, inflammatory wounds, radiation wounds, and others; b) skin grafts: to optimize graft integration to the bed; c) open abdomen; d) prevention of complications in closed incisions; e) instillation of solutions in contaminated or infected wounds.

NPT has become an important adjuvant method for the treatment of complex wounds ${ }^{17}$. In a retrospective study, Coltro et al. analyzed 1926 patients with complex wounds evaluated by the Plastic Surgery team of the Clinics Hospital, Faculty of Medicine, USP. Of these, 907 patients (47\%) were submitted to NPT as part of their treatment ${ }^{18}$.

NPT should applied on a clean wound, without devitalized tissue or after adequate debridement. It is also necessary to observe the contraindications to its use, reported later. Next, we present the main indications of NPT.

\section{Pressure ulcers}

Pressure ulcers (PU) are caused by the pressure maintained between a bone prominence and the patient's bed, leading to ischemia and necrosis of the involved tissues. They are common in patients with some mobility restriction, such as spinal cord injuries (paraplegic and quadriplegic) and patients under prolonged sedation. The most frequent sites of their development are the sacral, sciatic, trochanteric, calcaneal and occipital regions, among others (Figure 1).

The application of NPT in these wounds has the main objective of improving the local conditions for a later repairing surgery to obtain definitive cutaneous cover. This sequence is valid mainly in the cases of PU stages III and IV of the National Pressure Ulcer Advisory Panel (NPUAP), represented by deeper wounds, with muscular or bone exposure. Clinical reports such as that performed by Batra and Asseja ${ }^{19}$, however, show that even more complex wounds, when acute, could be treated only with NPT.

In 2002, Ford et al conducted a randomized, controlled study with 41 patients with deep PU, 


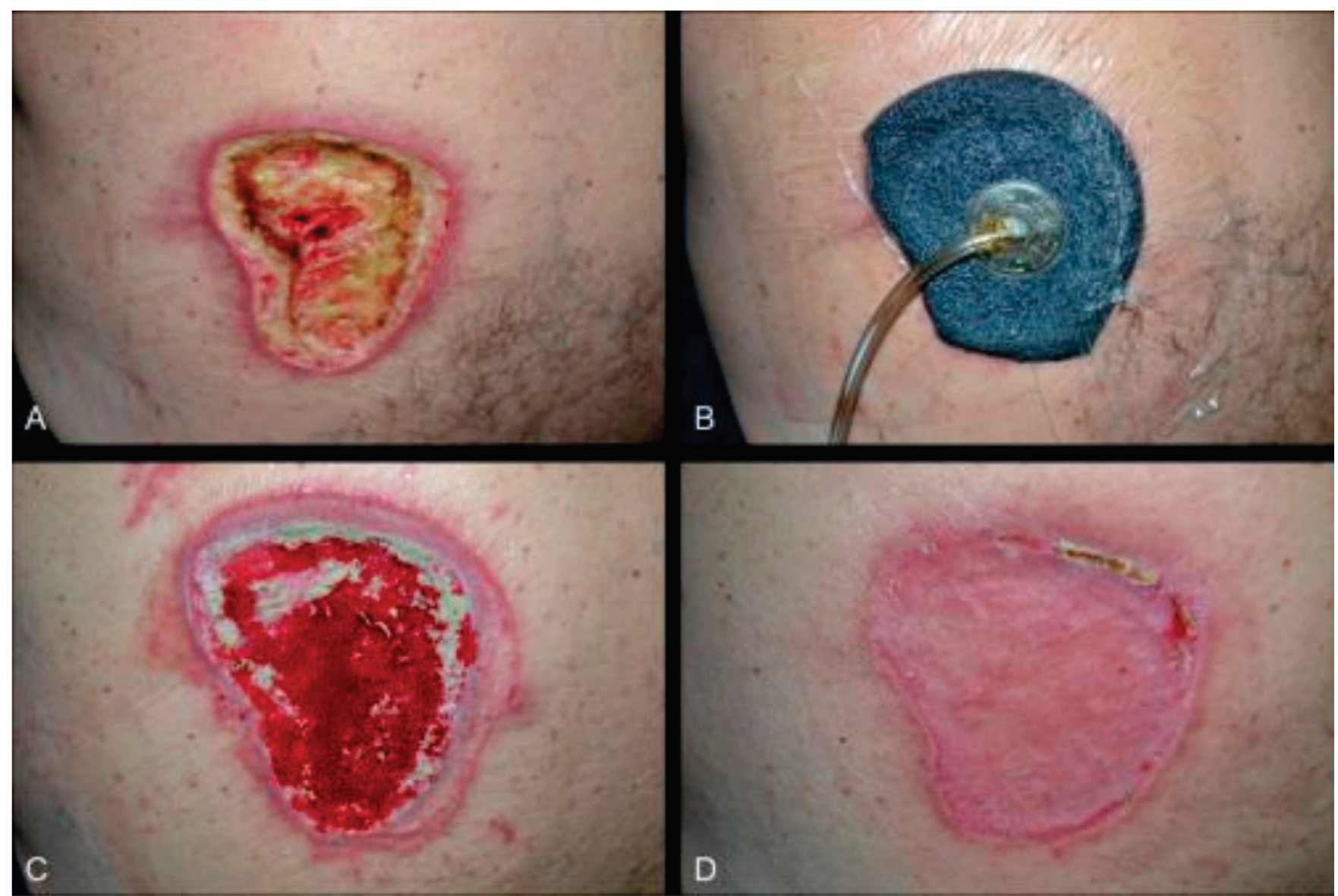

Figure 1. Male patient, 58 years old, paraplegic. A) Pressure ulcer in the left lumbar region, with wound bed filled with devitalized tissues; B) Application of NPT after surgical debridement; C) Appearance after NPT, with improvement of granulation tissue in the wound bed, before skin grafting; D) Postoperative aspect, with cutaneous cover of the wound, after satisfactory integration of the skin graft.

comparing NPT with topical healing promoter gels. The mean percentage reduction in ulcer volume was higher in the NPT group ( $51.8 \%$ vs. $42.1 \%, p=0.46$ ). The mean number of capillaries per wound bed field was also higher in the NPT group ( $p=0.75)$. The authors stated that NPT promotes healing and neovascularization when compared to topical gel treatment ${ }^{20}$.

Ashby et al., in 2012, conducted a randomized controlled trial in patients with PU grades III and IV, showing superior benefits of NTP in comparison with moist dressing ${ }^{4}$.

\section{Traumatic wounds}

Traumatic wounds include a group of acute, generally extensive, wounds with loss of cutaneous lining, associated or not with fractures. They are represented by degloving wounds (Figure 2), exposed fractures, wounds associated with muscular crushing, and others, affecting predominantly patients of economically active age.

The stimulation to the formation of granulation tissue in these wounds may be responsible for the reduction in the complexity of the reconstruction option. For example, NPT can promote the coverage of exposed bones and tendons by granulation tissue, allowing wound closure by means of skin grafting, rendering unnecessary the use flaps, with and without concomitant use dermal matrices ${ }^{21}$.

In 2012, Blum et al. evaluated the effect of NPT on the rate of infection in 220 patients with exposed tibial fractures, through a multicenter retrospective cohort study. The infection rate of the NTP group was lower $(8.4 \% \times 20.6 \%, p=0.01)$ compared with the group receiving conventional moist dressing ${ }^{22}$. In 2006, Yang et al. evaluated the efficacy of NPT in the Treatment of 34 patients with fasciotomy 


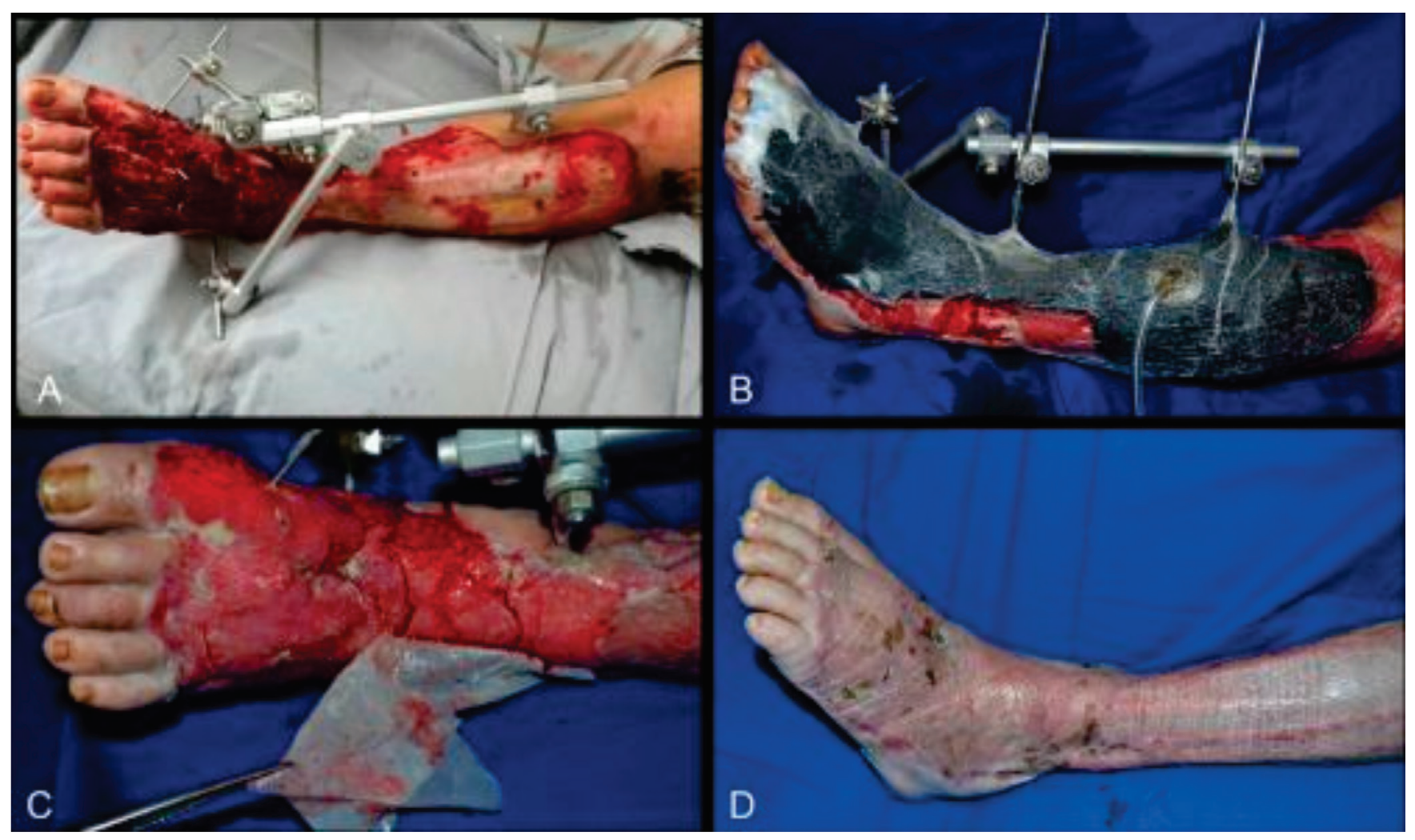

Figure 2. A 30-year-old male patient, victim of an automobile accident. A) Degloving (detachment injury) of the left leg; B) Application of NPT, allowing growth of granulation tissue on initially exposed bones and tendons; C) Aspect after maturation of the dermal matrix applied on the wound bed, demonstrating the removal of the silicone film to receive the skin graft; $D$ ) Postoperative aspect, with cutaneous cover of the wound, after satisfactory integration of the skin graft.

wounds after traumatic compartment syndrome. The mean time to final wound closure was 6.7 days for the NPT group and 16.1 days for the conventional moist dressing group $(p<0.05)^{23}$.

In 2013, Milcheski et al. studied 178 patients with traumatic lower limb wounds, most of them represented by degloving wounds. NPT significantly reduced the morbidity and healing time when compared with the previously used conventional dressings. According to the authors, NPT is useful in the treatment of acute traumatic wounds, acting as a bridge between emergency treatment and definitive cutaneous coverage ${ }^{24}$

\section{Surgical wounds (dehiscences)}

Dehiscences are the rupture or opening of a previously closed surgical incision that occur in $1 \%$ to $5 \%$ of surgeries and are associated with obesity, infection and tension in the suture line. In 2010, Petzina et al., retrospectively, analyzed 118 patients with mediastinitis and sternotomy dehiscence after cardiac surgery treated with NPT $(n=69)$ or with conventional therapy $(n=49)$. The group treated with NPT had a reduction in the mortality rate $(p=0.005)$ and in the rate of sternal reinfection $(p=0.008)$, in addition to a tendency of lower hospital stay $(p=0.08)$, reinforcing the idea of NTP as a first-line treatment for sternal wound infection ${ }^{25}$

In 2016, Morisaki et al. evaluated 73 patients who developed deep sternal wound infection after cardiac surgery. The authors stated that preparation of the wound bed with NTP followed by flap reconstruction was associated with improved prognosis and reduced mortality due to infection associated with sternotomy dehiscence ${ }^{26}$.

A precaution to be taken is the interposition of a fenestrated and non-adherent film between the surface of the sternal cleft wound and the foam, minimizing the possibility of injury to organs such as the heart or lungs. 


\section{Burns}

Third degree burns, after adequate debridement, may benefit from NPT, which may be applied as an adjuvant in bed preparation for subsequent skin grafting, or as a method of optimizing the integration of skin grafts $^{27}$. Patients with electrical trauma, which generally cause deep burns with extensive tissue destruction and progressive tissue damage, are also NPT candidates. The increase in blood perfusion secondary to NPT use is beneficial to burn injury. Kamolz et al. observed this in 2003, in a prospective study comparing the blood perfusion of burned hands that underwent conservative therapy and NPT. In the conservatively treated group, the authors observed reduced limb blood perfusion, which did not occur in the NPT-treated group ${ }^{28}$.

\section{Necrotizing wounds}

Necrotizing wounds are characterized by aggressive infection of deep tissues, usually of acute onset and rapid evolution, as occurs in cases of necrotizing fasciitis (called Fournier's gangrene when beginning in the perineum). The diagnosis should be early and treatment should be instituted as soon as possible, since such wounds are associated with a high mortality rate. The pillars of its treatment are based on extensive debridement and systemic antibiotic therapy. In 2011, Assenza et al. reviewed the literature and evaluated six patients with Fournier's gangrene treated with NPT. The authors affirmed that NPT accelerated the preparation of the wound, which allowed an earlier reconstruction, reduced the days of hospitalization, the discomfort of the patients and the number of medications, collaborating to improve their quality of life ${ }^{29}$.

Wounds associated with infection may benefit from specific dressings in which the polyurethane foam is impregnated with silver, which is released in a sustained fashion over the days of therapy and has bactericidal and bacteriostatic effects. In addition, such wounds may be treated with NPT associated with instillation of solutions, as discussed below.

\section{Diabetic wounds}

Wounds in diabetic patients are more common in the lower limbs, especially in the feet, and can be triggered by neuropathy, macroangiopathy and microangiopathy that are present in the pathophysiology of diabetes mellitus. In many cases, such wounds may evolve with deep tissue infection and gangrene, leading to amputation of the lower extremity. In 2005, Armstrong et al. carried out a multicenter, randomized, controlled clinical study (in 18 US hospitals), which included 162 diabetic patients after partial amputation of the foot, comparing NPT with conventional moist dressing. The authors verified that more patients healed in the NPT group in relation to the control group $(56 \% \times 39 \%$, $\mathrm{p}=0.04$ ). The wound healing rate (time until complete closure) was faster in the NTP group $(p=0.005)$, as well as the rate of granulation tissue formation $(p=0.002)^{30}$.

In 2008, Blume et al. evaluated 342 diabetic patients with foot wounds in a randomized, multicenter, controlled clinical study comparing a group that used NPT with one that used moist dressing. The authors demonstrated a higher proportion of complete wound closure in patients who used NPT $(43.2 \% \times 28.9 \%$, $\mathrm{p}=0.007)$ and lower a amputation rate in the same group ( $4.1 \%$ vs. $10.2 \%, p=0.035)^{31}$.

In 2015, Sajid et al. conducted a randomized, controlled trial with 278 patients with diabetic foot wounds comparing NPT with conventional moist dressing. After two weeks of treatment, the reduction of wound size was significantly greater in the group using NPT $(p<0.001)^{32}$.

\section{Venous ulcers}

Venous ulcers are a complication of chronic venous hypertension of the lower limbs of patients with varicose veins. These wounds can be large, often circumferential, and have low closure rates with conventional compressive therapy. They may remain for years or decades, causing a significant impact on patients' quality of life and on treatment costs ${ }^{33}$. In 2006, Vuerstaek et al. evaluated 60 patients with lower limb venous ulcers, comparing wound treatment with NPT or moist dressings in a randomized, controlled clinical study. Patients in the NPT group healed faster (29 days $x$ 45 days, $p=0.0001$ ), also reaching more quickly the time of wound bed preparation ( 7 days $\times 17$ days, $p=0.005)^{34}$. 
In 2012, Egemen et al. applied NPT in 20 patients with venous ulcers and found a rapid preparation of the bed, as well as an optimization of the subsequent integration of the skin graft ${ }^{35}$. Yang et al., in 2015, also compared the treatment of venous ulcers and demonstrated that NPT followed by partial skin grafting was more effective for the closure of these ulcers than conventional compressive therapy, with similar costs between the two treatments ${ }^{33}$.

\section{Skin grafts}

NPT is indicated over skin grafts to improve their adherence to the bed, to guarantee their immobility and to reduce the formation of seroma or hematoma, to optimize the integration of the skin graft to the wound bed. In such cases, NPT must always be administered in continuous mode. Polyvinyl alcohol foam is especially recommended in these cases because it has less adherence to the bed, facilitating its removal at the end of therapy, without interference with the integrated graft.

In 2010, Blume et al. performed a retrospective review of 142 patients treated with partial thickness skin grafts in reconstructive surgeries of the foot and ankle. Comparing NPT with conventional dressing, patients who used NPT presented greater graft integration ( $97 \%$ $x 84 \%, p=0.009)$ and less need for graft repetition due to integration failure $(5 \% \times 16 \%, p=0.006)^{36}$.

A randomized, controlled trial conducted by Moisidis et al. in 2004 evaluated the effects of NPT in comparison with conventional dressing in 22 patients undergoing partial thickness skin grafts. The results showed that graft integration was significantly better with NPT compared $(p<0.05)^{37}$.

In 2002, Scherer et al. performed a retrospective study including 61 patients submitted to partial thickness skin grafting. The results demonstrated that skin grafts that needed to be repeated due to losses were $3 \%$ in the NPT group and $19 \%$ in the conventional dressing group $(p=0.04)^{38}$.

\section{Open abdomen}

The open abdomen and the temporary abdominal closure are valuable techniques in the surgeon's arsenal and are indicated in the strategy of damage control, management of abdominal sepsis and prevention and treatment of abdominal compartment syndrome. In recent years, there has been an increase in NPT application in the abdominal wall closure of patients maintained in peritonostomy. As the foam cannot be in direct contact with the viscera, an interposed protective film is necessary. There are specific dressings for the application of NPT in open abdomen, such as the V.A.C. system. In this, the foam has extensions to reach the parietal and pelvic recesses (for drainage of the exudate), coupled with double protection with multipierced non-adherent film (to allow it to be positioned over the viscera), in addition to pre-cut foams, which are positioned on the first (to perform the medial approximation of the aponeurosis). The advantages of the NPT use in the open abdomen are the maintenance of the integrity of the abdominal wall, the prevention of the abdomen dominance loss over its visceral content, and peritoneal fluid removal.

In 2013, a prospective, multicenter study by Cheatham et al. included 168 patients with open abdomen who were treated with specific NPT or NPT made with packs and using the available vacuum system in the patient's bed (Barker's vacuum). The authors demonstrated that the V.A.C. system was associated with a lower 30 -day mortality rate $(14 \% \times 30 \%, p=0.01)$ and a higher rate of primary abdominal wall closure $(69 \% \times 51 \%, p=0.03)$ when compared with the Barker's vacuum ${ }^{39}$.

Kirkpatrick et al., in 2015, conducted a randomized, controlled study in 45 patients with open abdomen, comparing the use of V.A.C. system with Barker's vacuum. After 90 days, the authors verified that mortality was significantly lower in the group that used V.A.C. $(p=0.04)$, but the aponeurosis primary closure rate was similar in the two groups $(p=0.17)^{40}$.

\section{Prevention of dehiscence and surgical wound infection}

NPT can be used on closed surgical incisions to avoid dehiscence or infection of the operative wound. It is particularly indicated for patients at high 
risk of dehiscence or infection, such as obese, diabetic, smokers, and those whose wounds' edges have been under tension. In 2012, Stannard et al. conducted a randomized, prospective, multicenter clinical trial to evaluate the prevention of dehiscence and infection in 249 high-risk patients with extremity fractures. The authors compared NPT with conventional postoperative dressing. There was less dehiscence in the NTP group $(8.6 \% \times 16.5 \%, p=0.044)$, as well as a lower infection rate $(10 \% \times 19 \%, p=0.049)^{41}$.

\section{Solutions insulation}

The instillation of solutions in the wound bed can be associated with the NPT benefits. Instillation may be performed with isotonic solutions such as saline or lactated Ringer's or with solutions containing topical antimicrobials such as polyhexyl methylene biguanide (PHMB) or polyexanide, silver nitrate, hypochlorite and others. The main indications of NPT with instillation are contaminated or infected wounds. The time and frequency of the solution application in the wound bed can be controlled by the device parameters.

In 2011, Lehner et al. carried out a prospective, multicentric study associating NPT with instillation of PHMB in the treatment of wounds with infected orthopedic implants. After a four to six-month followup period, $86 \%$ of patients with acute infections and $80 \%$ with chronic infections kept their implants. The results suggest that NPT with instillation of PHMB can be effective as an adjuvant therapy in the treatment of these wounds, aiming at implant preservation, both in acute and chronic wounds ${ }^{42}$.

In 2016, Anghel et al. reviewed the evidence for the use of NTP with instillation, indicating a role for this therapy in helping to reduce hospital stay, number of debridements and treatment costs in patients with complex infected wounds ${ }^{43}$.

\section{Other indications}

NPT can also be used in inflammatory wounds (present in sickle cell anemia and in rheumatological diseases such as rheumatoid arthritis and scleroderma), radiation wounds (radiodermitis and radionecrosis), other vascular (artery, ischemic and neuropathic) ulcers, tunneled or cavitary wounds (to reduce dead space), as well as over the acellular dermal matrix (allowing its earlier integration into the wound bed).

\section{NPT CONTRAINDICATIONS}

The application of NPT may be harmful to the patient if contraindications are not observed. Huang et al. cite the main contraindications of NPT ${ }^{44}$, which may be absolute or relative: presence of necrosis on the wound bed; presence of tissue with malignancy; untreated osteomyelitis; non-enteric or non-explanted fistulas; exposure of vessels, nerves, organs or sites of anastomoses.

Despite these contraindications, there are reports of the application of NPT to exposed viscera, however with protection of these structures from direct contact with the polyurethane foam ${ }^{45}$. This protection may be performed by a non-adherent dressing or by a multipierced film. In addition, there are reports of NPT use as an adjuvant in the closure of bronchial fistula ${ }^{46}$.

\section{DIFFICULTIES AND INTERCORRENCES WITH NPT}

The application of NPT may be related to some difficulties or intercurrences, such as in the presence of external fixator, anticoagulated patients, sacral or excessively exudative wounds, and patients with pain during outpatient exchanges or in the hospital bed.

\section{Patient with external fixator}

Trauma patients who undergo orthopedic treatments may have the external fixator positioned near or in the wound bed (Figure 2). Although difficult to apply, this does not prevent the indication of NTP. An effective way of overcoming this difficulty is to cut the adhesive film into smaller fragments to accommodate between the fastener rods, seeking to completely seal the air intake. After installation of the dressing and with the device in operation, if there are still areas where there is air in the system and loss of vacuum, new reinforcing films can be applied, often guided by hearing the air escape points. There are devices that visually indicate in 
their panels if there is air intake, in addition to accusing air leak by an audible alarm.

\section{Patient under anticoagulation regimen}

Although it is not an absolute contraindication to NPT, its use in anticoagulated patients should be judicious. Increased blood flow in the treated area can result in bleeding, which is noted only by the rapid accumulation of blood in the reservoir. When it is indicated, it is imperative that NPT be done with the patient in a hospital stay and with broad clinical and surgical support for the diagnosis and early treatment of possible bleeding.

\section{Excessively Exudative Wounds}

NPT used in patients with excessively exudative wounds is associated with more frequent reservoir changes, increased risk of adhesive film detachment and air leakage, with loss of vacuum. In these cases, hospital admission may be more comfortable for the patient and the team due to the need for frequent exchange of the reservoir.

\section{Sacral wounds}

This location poses difficulty to NPT adjustment, since the displacement of the adhesive film from the region of the intergluteal groove is common, leading to air escape and loss of vacuum. The local humidity of the region is also a complicating factor to obtain complete seal of the dressing. To reduce this difficulty, one can apply a paste of hydrocolloid to fill and regularize folded areas, such as the intergluteal groove. After this paste dries, the adhesive film is placed more easily, reducing the risk of air entering the system.

\section{Intermittent therapy}

NPT in intermittent mode is generally set at $5: 2$, that is, five minutes running at subatmospheric pressure and two minutes at rest. Although experimental studies have shown a greater formation of granulation tissue and greater retraction of the wound edges with intermittent therapy ${ }^{3}$, its application presents some difficulties. When the negative pressure is not in place', there is a risk of accumulation of exudate in the wound bed, leading to detachment of the adhesive film. After the resumption of NPT, there is air leakage in the dressing and loss of vacuum. This situation, especially in patients treated in an outpatient setting, causes great harm by making continuity of therapy impossible. In addition, the application of intermittent NTP may be painful and intolerable for some patients, especially in the periods when therapy is resumed, at the end of rest cycles.

\section{Pain during the exchanges}

Patients may experience pain during dressing changes performed outside the operating room and without anesthesia. It is common for the foam to be closely adhered to the wound bed, leading to pain and bleeding during withdrawal. To reduce this effect, NPT can be switched off a few hours before the dressing is removed. In addition, the foam may be soaked with saline after removal of the adhesive film, or even by the plastic connector prior to removal of the film. Such techniques facilitate the removal of foam, with less trauma and less pain.

Another alternative is the interposition of a fenestrated and non-adherent film between the surface of the wound and the foam, minimizing the possibility of pain during the exchanges. However, there is evidence that interposition of any material between the foam and the wound bed can reduce the intensity of the negative pressure applied by the system.

\section{CONCLUSION}

Since its introduction, NPT has become a well-established adjuvant method in the treatment of complex wounds. Despite the accumulation of evidence in recent years, NPT still raises doubts for many surgeons. Although its application is not complex, adequate knowledge of its mechanism of action and its main indications can optimize and rationalize its use, leading to more effectively wound resolution. NPT must compose the therapeutic arsenal of surgeons for the treatment of the most varied complex wounds. 


\title{
R E S U M O
}

\begin{abstract}
O objetivo desse estudo é avaliar a eficácia da terapia por pressão negativa (TPN) no tratamento de feridas complexas, com ênfase em seus mecanismos de ação e principais indicações terapêuticas. Foi realizada revisão na base de dados Pubmed / Medline, em artigos publicados de 1997 a 2016, e selecionados os mais relevantes. O mecanismo de ação da TPN envolve efeitos físicos, como o aumento da perfusão, controle do edema e do exsudato, redução das dimensões da ferida e depuração bacteriana, e biológicos, como o estímulo à formação de tecido de granulação, microdeformações e redução da resposta inflamatória local. As principais indicações da TPN são as feridas complexas como úlceras por pressão, feridas traumáticas, deiscências de ferida operatória, queimaduras, feridas necrotizantes, úlceras venosas, feridas diabéticas, os enxertos de pele, o abdome aberto, na prevenção de complicações em incisões fechadas e na associação com instilação de soluções em feridas infectadas.
\end{abstract}

Descritores: Tratamento de Ferimentos com Pressão Negativa. Ferimentos e Lesões. Técnicas de Fechamento de Ferimentos. Úlcera por Pressão. Deiscência da Ferida Operatória.

\section{REFERENCES}

1. Ferreira MC, Tuma P Jr, Carvalho VF, Kamamoto F. Complex wounds. Clinics (Sao Paulo). 2006;61(6):571-8.

2. Argenta LC, Morykwas MJ. Vacuum-assisted closure: a new method for wound control and treatment: clinical experience. Ann Plast Surg. 1997;38(6):56376; discussion 577

3. Malmsjö M, Gustafsson L, Lindstedt S, Gesslein B, Ingemansson R. The effects of variable, intermittent, and continuous negative pressure wound therapy, using foam or gauze, on wound contraction, granulation tissue formation, and ingrowth into the wound filler. Eplasty. 2012;12:e5.

4. Ashby RL, Dumville JC, Soares MO, McGinnis E, Stubbs N, Torgerson DJ, et al. A pilot randomised controlled trial of negative pressure wound therapy to treat grade III/IV pressure ulcers [ISRCTN69032034]. Trials. 2012;13:119.

5. Saxena V, Hwang CW, Huang S, Eichbaum Q, Ingber D, Orgill DP. Vacuum-assisted closure: microdeformations of wounds and cell proliferation. Plast Reconstr Surg. 2004;114(5):1086-96; discussion 1097-8.

6. Fraccalvieri M, Zingarelli E, Ruka E, Antoniotti U, Coda $R$, Sarno A, et al. Negative pressure wound therapy using gauze and foam: histological, immunohistochemical and ultrasonography morphological analysis of the granulation tissue and scar tissue. Preliminary report of a clinical study. Int Wound J. 2011;8(4):355-64.

7. Malmsjö M, Lindstedt S, Ingemansson R. Effects of foam or gauze on sternum wound contraction, distension and heart and lung damage during neg- ative-pressure wound therapy of porcine sternotomy wounds. Interact Cardiovasc Thorac Surg. 2011;12(3):349-54.

8. Birke-Sorensen H, Malmsjo M, Rome P, Hudson D, Krug E, Berg L, et al. Evidence-based recommendations for negative pressure wound therapy: treatment variables (pressure levels, wound filler and contact layer)--steps towards an international consensus. J Plast Reconstr Aesthet Surg. 2011;64 Suppl:S1-16.

9. Huang S, Chen CS, Ingber DE. Control of cyclin D1, p27(Kip1), and cell cycle progression in human capillary endothelial cells by cell shape and cytoskeletal tension. Mol Biol Cell. 1998;9(11):3179-93.

10. Chen SZ, Li J, Li XY, Xu LS. Effects of vacuum-assisted closure on wound microcirculation: an experimental study. Asian J Surg. 2005;28(3):211-7.

11. Norbury K, Kieswetter K. Vacuum-assisted closure therapy attenuates the inflammatory response in a porcine acute wound healing model. Wounds. 2007;19(4):97-106.

12. Ichioka S, Watanabe $H$, Sekiya $N$, Shibata $M, N a-$ katsuka T. A technique to visualize wound bed microcirculation and the acute effect of negative pressure. Wound Repair Regen. 2008;16(3):460-5.

13. Kairinos N, Voogd AM, Botha PH, Kotze T, Kahn D, Hudson DA, et al. Negative-pressure wound therapy II: negative-pressure wound therapy and increased perfusion. Just an illusion? Plast Reconstr Surg. 2009;123(2):601-12.

14. Glass GE, Nanchahal J. The methodology of negative pressure wound therapy: separating fact from fiction. J Plast Reconstr Aesthet Surg. 2012;65(8):989-1001. 
15. Mouës $C M$, Vos $M C$, van den Bemd GJ, Stijnen T, Hovius SE. Bacterial load in relation to vacuum-assisted closure wound therapy: a prospective randomized trial. Wound Repair Regen. 2004;12(1):11-7.

16. Boone D, Braitman E, Gentics C, Afthinos J, Latif J, Sordillo $E$, et al. Bacterial burden and wound outcomes as influenced by negative pressure wound therapy. Wounds. 2010;22(2):32-7.

17. Anghel EL, Kim PJ. Negative-pressure wound therapy: a comprehensive review of the evidence. Plast Reconstr Surg. 2016;138(3 Suppl):129S-37S.

18. Coltro PS, Ferreira MC, Batista BPSN, Nakamoto HA, Milcheski DA, Tuma Júnior P. Atuação da Cirurgia Plástica no tratamento de feridas complexas. Rev Col Bras Cir. 2011;38(6):381-6.

19. Batra RK, Aseeja V. VAC therapy in large infected sacral pressure ulcer grade iv-can be an alternative to flap reconstruction? Indian J Surg. 2014;76(2):162-4.

20. Ford CN, Reinhard ER, Yeh D, Syrek D, De Las Morenas A, Bergman SB, et al. Interim analysis of a prospective, randomized trial of vacuum-assisted closure versus the healthpoint system in the management of pressure ulcers. Ann Plast Surg. 2002;49(1):55-61; discussion 61.

21. Farina JA Jr, de Almeida CE, Marques EG, Jorge $J \mathrm{~L}$, Lima RV. Letter to the editor: Negative pressure wound therapy in grade IIIB tibial fractures: fewer infections and fewer flap procedures? Clin Orthop Relat Res. 2015;473(11):3682-3.

22. Blum ML, Esser M, Richardson M, Paul E, Rosenfeldt FL. Negative pressure wound therapy reduces deep infection rate in open tibial fractures. J Orthop Trauma. 2012;26(9):499-505.

23. Yang CC, Chang DS, Webb LX. Vacuum-assisted closure for fasciotomy wounds following compartment syndrome of the leg. J Surg Orthop Adv. 2006;15(1):19-23.

24. Milcheski DA, Ferreira MC, Nakamoto HA, Pereira DD, Batista BN, Tuma Jr P. Uso da terapia por pressão subatomsférica em feridas traumáticas agudas. Rev Col Bras Cir. 2013;40(5):392-7.
25. Petzina R, Hoffmann J, Navasardyan A, Malmsjö M, Stamm C, Unbehaun A, et al. Negative pressure wound therapy for post-sternotomy mediastinitis reduces mortality rate and sternal re-infection rate compared to conventional treatment. Eur J Cardiothorac Surg. 2010;38(1):110-3.

26. Morisaki A, Hosono M, Murakami T, Sakaguchi M, Suehiro $Y$, Nishimura $S$, et al. Effect of negative pressure wound therapy followed by tissue flaps for deep sternal wound infection after cardiovascular surgery: propensity score matching analysis. Interact Cardiovasc Thorac Surg. 2016;23(3):397-402.

27. Teng SC. Use of negative pressure wound therapy in burn patients. Int Wound J. 2016;13 Suppl 3:15-8.

28. Kamolz LP, Andel H, Haslik W, Winter W, Meissl $G$, Frey M. Use of subatmospheric pressure therapy to prevent burn wound progression in human: first experiences. Burns. 2004;30(3):253-8.

29. Assenza M, Cozza V, Sacco E, Clementi I, Tarantino B, Passafiume F, Valesini L, et al. VAC (Vacuum Assisted Closure) treatment in Fournier's gangrene: personal experience and literature review. Clin Ter. 2011;162(1):e1-5.

30. Armstrong DG, Lavery LA; Diabetic Foot Study Consortium. Negative pressure wound therapy after partial diabetic foot amputation: a multicentre, randomised controlled trial. Lancet. 2005;366(9498):1704-10.

31. Blume PA, Walters J, Payne W, Ayala J, Lantis J. Comparison of negative pressure wound therapy using vacuum-assisted closure with advanced moist wound therapy in the treatment of diabetic foot ulcers: a multicenter randomized controlled trial. Diabetes Care. 2008;31(4):631-6.

32. Sajid MT, Mustafa Qu, Shaheen N, Hussain SM, Shukr I, Ahmed M. Comparison of negative pressure wound therapy using vacuum-assisted closure with advanced moist wound therapy in the treatment of diabetic foot ulcers. J Coll Physicians Surg Pak. 2015;25(11):789-93.

33. Yang CK, Alcantara S, Goss S, Lantis JC 2nd. Cost analysis of negative-pressure wound therapy with instillation for wound bed preparation preced- 
ing split-thickness skin grafts for massive (>100 $\mathrm{cm}(2))$ chronic venous leg ulcers. J Vasc Surg. 2015;61(4):995-9.

34. Vuerstaek JD, Vainas T, Wuite J, Nelemans P, Neumann $\mathrm{MH}$, Veraart JC. State-of-the-art treatment of chronic leg ulcers: a randomized controlled trial comparing vacuum-assisted closure (V.A.C.) with modern wound dressings. J Vasc Surg. 2006;44(5):1029-37; discussion 1038.

35. Egemen O, Ozkaya O, Ozturk MB, Aksan T, Orman Ç, Akan M. Effective use of negative pressure wound therapy provides quick wound-bed preparation and complete graft take in the management of chronic venous ulcers. Int Wound J. 2012;9(2):199205.

36. Blume PA, Key JJ, Thakor P, Thakor S, Sumpio B. Retrospective evaluation of clinical outcomes in subjects with split-thickness skin graft: comparing V.A.C.Oे therapy and conventional therapy in foot and ankle reconstructive surgeries. Int Wound J. 2010;7(6):480-7.

37. Moisidis E, Heath T, Boorer C, Ho K, Deva AK. A prospective, blinded, randomized, controlled clinical trial of topical negative pressure use in skin grafting. Plast Reconstr Surg. 2004;114(4):917-22.

38. Scherer LA, Shiver S, Chang M, Meredith JW, Owings JT. The vacuum assisted closure device: a method of securing skin grafts and improving graft survival. Arch Surg. 2002;137(8):930-3; discussion 933-4.

39. Cheatham ML, Demetriades D, Fabian TC, Kaplan MJ, Miles WS, Schreiber MA, et al. Prospective study examining clinical outcomes associated with a negative pressure wound therapy system and Barker's vacuum packing technique. World J Surg. 2013;37(9):2018-30.

40. Kirkpatrick AW, Roberts DJ, Faris PD, Ball CG, Kubes $P$, Tiruta $C$, et al. Active negative pressure peritoneal therapy after abbreviated laparotomy: the intraperitoneal vacuum randomized controlled trial. Ann Surg. 2015;262(1):38-46.

41. Stannard JP, Volgas DA, McGwin G 3rd, Stewart RL, Obremskey W, Moore $T$, et al. Incisional negative pressure wound therapy after high-risk lower extremity fractures. J Orthop Trauma. 2012;26(1):37-42.

42. Lehner B, Fleischmann W, Becker R, Jukema GN. First experiences with negative pressure wound therapy and instillation in the treatment of infected orthopaedic implants: a clinical observational study. Int Orthop. 2011;35(9):1415-20.

43. Anghel EL, Kim PJ, Attinger CE. A solution for complex wounds: the evidence for negative pressure wound therapy with instillation. Int Wound J. 2016;13 Suppl 3:19-24.

44. Huang C, Leavitt T, Bayer LR, Orgill DP. Effect of negative pressure wound therapy on wound healing. Curr Probl Surg. 2014;51(7):301-31.

45. Sermoneta D, Di Mugno M, Spada PL, Lodoli C, Carvelli ME, Magalini SC, et al. Intra-abdominal vacuum-assisted closure (VAC) after necrosectomy for acute necrotising pancreatitis: preliminary experience. Int Wound J. 2010;7(6):525-30.

46. Nunes RB, Müller Neto BF, Cipriano FEG, Coltro PS, Farina Júnior JA. Fechamento de fistula brônquica com uso da terapia por pressão negativa: um tratamento viável e custo-efetivo. Rev Col Bras Cir. 2016;43(4):292-4.

Received in: 07/11/2016

Accepted for publication: 01/12/2016

Conflict of interest: none.

Source of funding: none.

\section{Mailing address:}

Pedro Soler Coltro

E-mail: pscoltro@hotmail.com / psc@usp.br 